\title{
A systematic material selection process applied to a luminaire diffuser
}

\author{
C Javierre $^{\mathrm{a}}$, D Elduque ${ }^{\mathrm{a}}$, VM Camañes $^{\mathrm{a}}$ and J Cuartero ${ }^{\mathrm{b}}$ \\ ${ }^{a}$ i+ aitiip , University of Zaragoza, Zaragoza, Spain \\ ${ }^{\mathrm{b}}$ Department of Mechanical Engineering, University of Zaragoza, Zaragoza, Spain
}

Short title: Material selection for diffuser design

Received 2 December 2014; Revised 9 February 2015; Accepted

This paper presents a systematic material selection process for technical, environmental and economic criteria. This methodology has been applied to the design of a weatherproof luminaire. The materials selected for the production of this diffuser were characterized to obtain their mechanical properties and to perform exhaustive research on impact analysis by means of finite element modelling. Also an economic analysis and an ecological impact assessment have been performed. Thanks to this working methodology, a final design of the diffuser has been developed having the optimum thickness to achieve the mechanical specifications and minimize the environmental impact and the cost of the diffuser.

Address for correspondence: Carlos Javierre, i+ aitiip , University of Zaragoza, C/ María de Luna 3, 50018 Zaragoza, Spain

E-mail: carlos.javierre@unizar.es 


\section{Introduction}

The weatherproof luminaire is an important product for a number of industrial and public working areas, such as factories, cold storage rooms and parking lots. A weatherproof luminaire has special requirements, different from those specified for a typical indoor luminaire used in offices, museums etc. In the typical indoor luminaire the aesthetics, the light diffusion and other factors are of special relevance, but in an industrial weatherproof luminaire it is its functionality and low cost that are the main factors.

Weatherproof luminaires usually consist of a housing, a light diffuser, closing clips and a gasket compressed by the other parts (Figure 1). These four elements protect all the electrical systems from mechanical impact, water, dust and humidity.

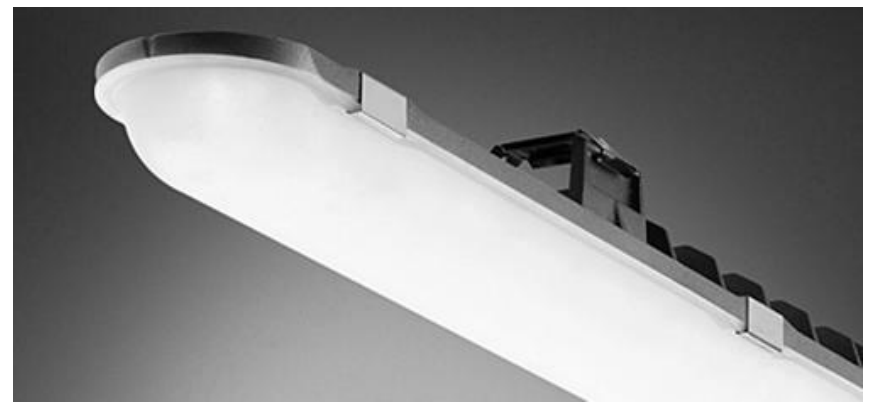

Figure 1. The Nextrema weatherproof luminaire

Weatherproof luminaires are tested in different ways to ensure that they comply with the established requirements so that they can be sold under different criteria, such as the weatherproof and dustproof standards (IP rating), or the impact resistance standard. The impact resistance of a luminaire is determined by the IK 
number, which is related to a specific amount of impact energy which can be withstood by the luminaire diffuser. This impact test is performed by hitting the diffuser with a mass thrown from different heights depending on the IK number which is required. Table 1 shows the energy of the impact corresponding to the IK number ${ }^{1}$.

Light-diffusers are traditionally injection molded with transparent commodity thermoplastic materials like polymethylmethacrylate (PMMA), polycarbonate (PC) or Styrene-acrylonitrile (SAN) ${ }^{2}$. These materials have got different properties but all of them can be used to produce high quality light diffusers. Researchers and producers are constantly developing new polymer blends that will also improve their properties such as impact resistance ${ }^{3}$. The decision to use one or other material depends on different criteria, mainly functional, technical and economic ones. From a functional point of view, a chemical substance's resistance, rigidity and impact strength are essential properties. Traditionally, PC is the preferred polymer when we talk about impact resistance. Acrylic polymers, like PMMA, have good optical properties, but they are worse from a mechanical point of view, even though they can be reinforced by adding elements in their formula although this increases the price. Finally, SAN is the most economic polymer, but with worse impact resistance, even though its rigidity is higher than PC and PMMA. In order to foresee the diffuser behaviour against the IK test, impact simulations must be performed by means of computer-aided engineering (CAE) simulation software which analyses the impact resistance thanks to the finite element method (FEM). These simulations are complex, especially due to the material characterization and the accuracy of the simulation model which is needed to obtain results that can be used to make appropriate design decisions. FEM analysis has also been widely used for weight reduction in other injection molded parts ${ }^{4}$.Other researchers have used CAE tools to improve PC injected parts ${ }^{5}$. 
In addition to FEM analysis, over the last few years ecological criteria are being strongly taken into account in the design process. When performing an environmental impact assessment of a product, several factors related to the materials, the production processes and transportation must be taken into account. In a plastic part like a diffuser, which is produced by injection molding, the material impact is one of the main factors to be taken into account during the design process.

The aim of this paper is to show the material selection process for a luminaire diffuser intended for use with a LED light source. Different types of CAE software have been used to perform simulations, analyzing different design and material options from functional, processing, economic and ecological points of view. This analysis will be performed taking into account all the criteria in a systematic way, considering all the main design factors.

\section{Methodology}

Figure 2 shows the procedure which is going to be followed in order to optimize the design. This procedure is explained in detail in the following sections. 


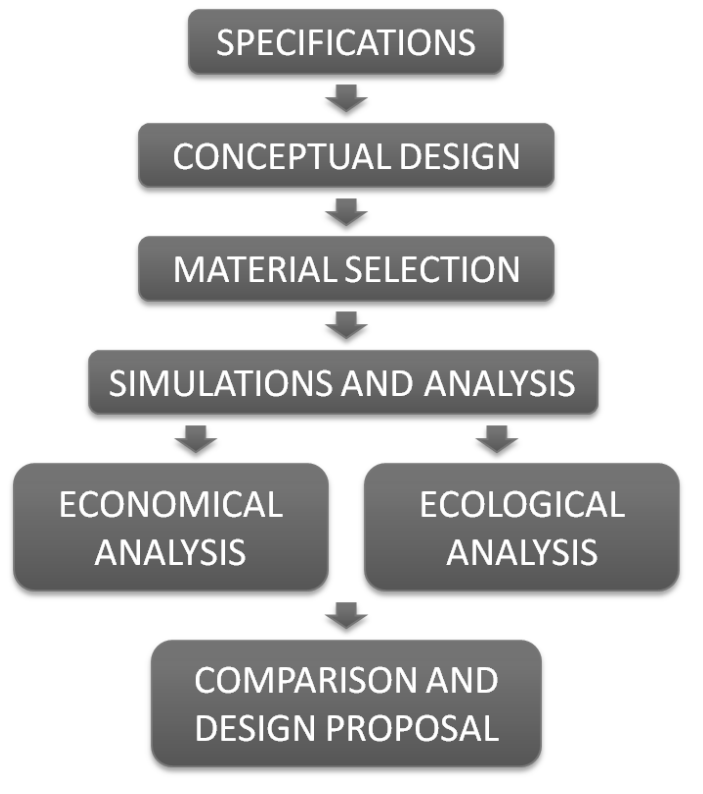

Figure 2. Working methodology diagram

\subsection{Specification}

The design of the diffuser is mainly based on fulfilling the requirements of the specification. These requirements include the diffuser's interactions with other parts of the luminaire, the tests it has to pass, the economic restrictions, and other technical characteristics.

\subsection{Conceptual design}

From the basic geometry, an initial design is created with the required shape and dimensions according to the functional specifications. At this stage, some detailed parameters like diffuser thickness, are not relevant. They will be properly defined in the following steps, where the optimization will be performed.

\subsection{Material selection}


From experience, a list of viable materials is selected, with traditional and recently developed materials (Both transparent and opal grades of PC, PMMA and SAN).

\subsection{Simulations and analysis}

Several simulations and analyses have to be performed in order to optimize a new diffuser design, including optical considerations, manufacturability, thermal behaviour, the effect of manufacturing tolerances etc. Also, the most critical mechanical property for this luminaire, its impact resistance, is analyzed. Taking the first conceptual design as a reference, its impact behaviour is analyzed for the selected materials and for a wide range of different thicknesses.

\subsubsection{Material testing methodology.}

A luminaire's impact behaviour is based on the impact of a steel ball. Such a ball is dropped from a 1 metre height so the impact velocity is $4.47 \mathrm{~m} / \mathrm{sec}$, which could lead to a high strain velocity at the material. Strain velocity might be not so high for all load cases, but is wise to consider such a possibility bearing in mind how plastics are affected by that material property. Strain rate on plastics is extremely important because it modifies quite a lot of mechanical properties such as elastic modulus and strength. Changes of mechanical properties at different strain rates is something that should always be considered when talking about plastics. Generally speaking, strength and elastic modulus should be higher for high strain rates. Particularly for PC, both elastic modulus and ultimate strength are much higher at high strain rate. That is the reason for scheduling a complete set of mechanical tests at different strain rates. ISO 
527 requires a tensile test for plastics at $1 \mathrm{~mm} / \mathrm{min}^{6}$, which leads to a quite low strain rate velocity for the standard specimen.

The tests at high speed are usually made by a Hopkinson bar test. These tests are difficult to perform and must be done with a specific machine, usually quite an expensive one. Lacking such a testing facility at the University of Zaragoza, we decided to perform tensile tests at the maximum speed possible, for each material. A series of tests were made in order to find out what was the maximum speed that could be achieved. The maximum speed achieved was $2000 \mathrm{~mm} / \mathrm{min}$. That corresponds to about a $0.25 \mathrm{~s}^{-1}$ strain rate, which is relatively low since the literature ${ }^{7}$ speaks of a strain rate of $5000 \mathrm{~s}^{-1}$. The samples are not examined under all tensile conditions. Tensile testing has been considered in order to obtain the mechanical properties of the material. Therefore, a full range of testing, bearing in mind strain rate, is performed. Strain rate analysis is needed in order to simulate correctly the impact behaviour of the material. Strain rate it is critical for high velocity propagation testing. Tensile properties coming from tensile analysis are considered to be isotropic. The injection molding procedure used for manufacture should guarantee very similar tensile properties for both samples and measured specimen.

\subsubsection{Simulation methodology for mechanical impact.}

Two commercial software programs were used to carry out the finite element analysis. The model preprocess was performed using MSC.Patran ${ }^{8}$ and the calculation and post-processing was performed using the code ABAQUS / Explicit ${ }^{9}$. Both programs are recognized leaders in their respective fields, and ABAQUS in the selected mode is an explicit finite element code. Boundary conditions have been modeled in order to simulate perfectly the coupling of the housing by clips. Moreover, the other boundary 
condition is a falling steel ball at $4.47 \mathrm{~m} / \mathrm{s}$. Figure 3 shows the boundary condition, the ball and the whole model. The same figure shows a test of a diffuser where catastrophic failure occurred. Each material is assigned to the appropriate zone. There is another boundary condition that is the boundary condition of contact between the ball and the diffuser. The properties of the materials specified in the program are activated with the option of removing failed elements to simulate catastrophic failure in the case that total failure occurs.

Bearing in mind the crash type analysis needed, the Abaqus/Explicit option of was selected. Explicit dynamics is a solution method for integrating the equations of motion through time. Dynamic equilibrium equations are written with the inertial forces isolated from the other forces. These equations apply to the behaviour of any mechanical system, and include all possible nonlinearities (contact, nonlinear materials, large deformations). The forward Euler or central difference algorithm is used combined with a lumped mass matrix to make the explicit finite element program work.

Abaqus/Explicit is a finite element analysis product that is particularly well-suited to simulate brief transient dynamic events such as consumer electronics drop testing, automotive crashworthiness, and ballistic impact. The ability of Abaqus/Explicit to effectively handle severely nonlinear behaviour such as contact makes it very attractive for the simulation of many quasi-static events, such as rolling of hot metal and slow crushing of energy absorbing devices. 


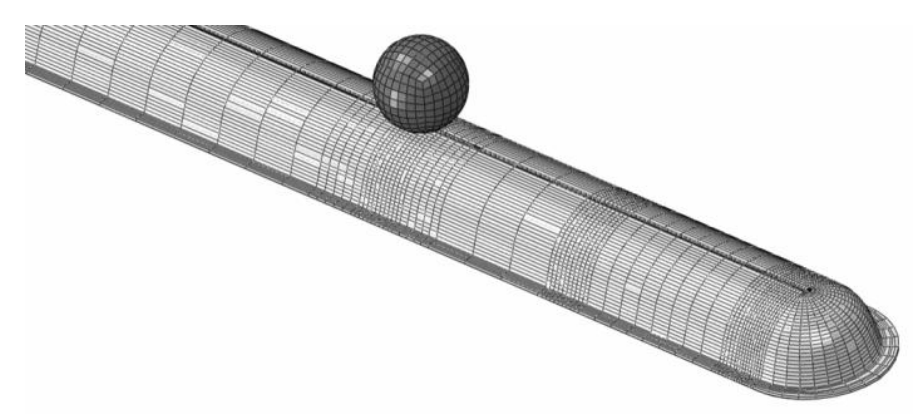

Figure 3. Simulation model and impact test

Once the characterization of the materials is finished, the simulations of impact can be carried out. The calculations will reproduce the impact test at the centre and at the end of the diffuser. Results will focus on the analysis of stress and especially in the strain that appear in the material due to impact. If the strain is higher than the allowable value for the material the element will be deleted showing the same behaviour as actual testing. The area cracked will be shown without these elements so the simulation should show the damaged areas perfectly.

\subsubsection{Environmental impact assessment methodology}

Once the design complies with the technical and functional specifications, ecological factors can be assessed. In recent years, there has been an increasing interest in reducing the environmental impact of products. Ecodesign has become a important factor in new product developments as European Legislation started to ban the use of hazardous substances $(\mathrm{RoHS})^{10}$, control chemical products (REACH) ${ }^{11}$, enhance the recyclability of electrical and electronic products (WEEE) $)^{12}$ and also introduced ecodesign requirements in energy-using and energy-related products (EuP and $\mathrm{ErP})^{13,14}$. 
Life cycle assessment methodology has been used by a wide number of researchers, being applied to a broad number of products, from wind turbines ${ }^{15}$ to food packaging ${ }^{16}$, plastic injection molds ${ }^{17}$, or fluorescent lamp luminaires ${ }^{18}$. To compare the different design options, two different life cycle assessment methodologies are used: Ecolndicator 99 v2.09 $(\mathrm{H} / \mathrm{A})^{19}$, a damage oriented methodology that has been widely used and is recommended for designers, and the carbon footprint. The Ecolndicator 99 weights several environmental impacts into a single value, allowing easier comparisons between design options. The carbon footprint has been calculated with the values of the IPCC 2007 GWP $100 a^{20}$.

A simplified life cycle assessment, based on the ISO $14040^{21}$ and ISO $14044^{22}$ standards, is performed in order to calculate and compare the environmental impact of each diffuser design. It is beyond the scope of this study to assess the environmental impact of the rest of the weatherproof luminaire, as changes in the diffuser design are assessed independently. Raw materials use, production processes, transportation and end-of-life have been taken into account. As different materials have different densities, for the same thickness a different weight is obtained, influencing the whole life cycle. The environmental assessment is performed using SimaPro v7.3.3 ${ }^{23}$, software that allows researchers to compare different materials and thickness.

\subsubsection{Cost analysis methodology}

In order to obtain the cost of the diffuser, a methodology developed by the authors is applied. This methodology has been implemented in software called $\mathrm{APPPI}^{24}$, specially developed for injection molded plastic parts. This software calculates the cost of a designed part taking into account different parameters such as the material, geometry and process conditions. The total cost of the part is calculated 
taking into account raw material cost, mould cost and processing costs, which include machine costs, labour cost and additional operations in the injection process such as the tuning of the machine and rejections, as shown in Equation 1.

$$
\begin{aligned}
& \text { Total cost }=(\text { Raw mat. }+ \text { mould }+ \text { machine }+ \text { handwork }+ \\
& + \text { process }+ \text { other proc. }) \cdot\left(\frac{100}{100-\text { defective parts }}\right)
\end{aligned}
$$

As this analysis is comparative between different parts, mould cost has not been taken into account as it does not affect the final results. Material cost is calculated using the weight and price of each material. These data were provided by Zalux. Injection cost has been optimized with the APPPI software, as this program chooses the optimal injection machine having taken into account thickness, volume, the material of the part, and also other parameters such as projected area, flow length and cycle time ${ }^{25}$.

\subsubsection{Comparison and design selection}

All the previous phases help us generate a comparison report and select the optimal design according to technical, economic and ecological criteria. Based on this comparison report, the final design is decided.

\section{Results and discussion}

\subsection{Selected light diffuser specification}


This methodology has been applied to a weatherproof luminaire that has been developed recently. This luminaire, called Nextrema, is based on LED technology. The design of the diffuser was performed to meet the requirements of the specification of the luminaire and the diffuser. These are the main requirements:

- Compatible geometry with the housing and clips

- Smooth and round shape

- Optimized weight and cost. Lower than a previously designed diffuser

- Impact resistance: $1 K 08^{1}$

\subsection{Conceptual design}

With these requirements, a first geometry for the diffuser was designed. This first iteration of the design was created with an initial thickness of $2 \mathrm{~mm}$, based on experience with this kind of products. The geometry of this new diffuser has significant changes compared to diffusers used in fluorescent luminaires. This means that the diffuser geometry and thickness must be validated with FEM simulations before taking it into production. With this thickness, the volume of the part is 280 cubic centimetres.

\subsection{Material selection}

Based on experience in the development of similar products, four possible materials were selected: SAN, PMMA, Conventional PC and OPAL PC. This last material was the one used in the previous generation of LED luminaires developed by the manufacturer, and has been added to the study for comparison reasons, as the three first materials have better transmission factors. From the optical performance point of view there are some differences between non-opal materials. The optical transmittance for $2 \mathrm{~mm}$ thickness varies from $92 \%$ in PMMA to $87 \%$ in PC, creating 
small differences in the luminaire efficiency. All these materials are currently used for similar optical applications.

The new design includes a prismatic pattern that generates a low unified glare rating (UGR) without using an opal tint. When the UGR value of the design is critical, OPAL PC may be used, although it noticeably reduces the optimal transmittance and efficiency. It allows a smooth inner diffuser surface with uniform thickness, instead of having a prismatic inner surface.

The effect of weathering and UV degradation on the material is avoided by using polymers that are additivated. The loss of mechanical properties and the colour changes (yellowing) are prevented by using polymer grades that guarantee stable material behaviour during the luminaire's life cycle.

\subsection{Simulations and analysis}

\subsubsection{Mechanical analysis}

First, stable test specimens were manufactured. The process was to inject test specimens according to ISO- $527^{6}$ for the characterization of materials. The material was supplied by the company Zalux and tensile tests were performed on the hydraulic universal tensile machine, Instron 8032, at the Mechanical Engineering Department of the University of Zaragoza. Figure 4 shows opal PC specimens before and after testing. The tests were performed at the speed indicated by ISO-527. A series of tests were done with gradually increasing test speeds up to the maximum speeds allowed by the hardware. From the analysis of the influence of the test speed on each material, and based on the literature, the material behaviour was established. Figure 5 shows the 
curves obtained for each material at the ISO test speed and Figure 6 shows the PC curves extrapolated for use in simulations for different strain rates.

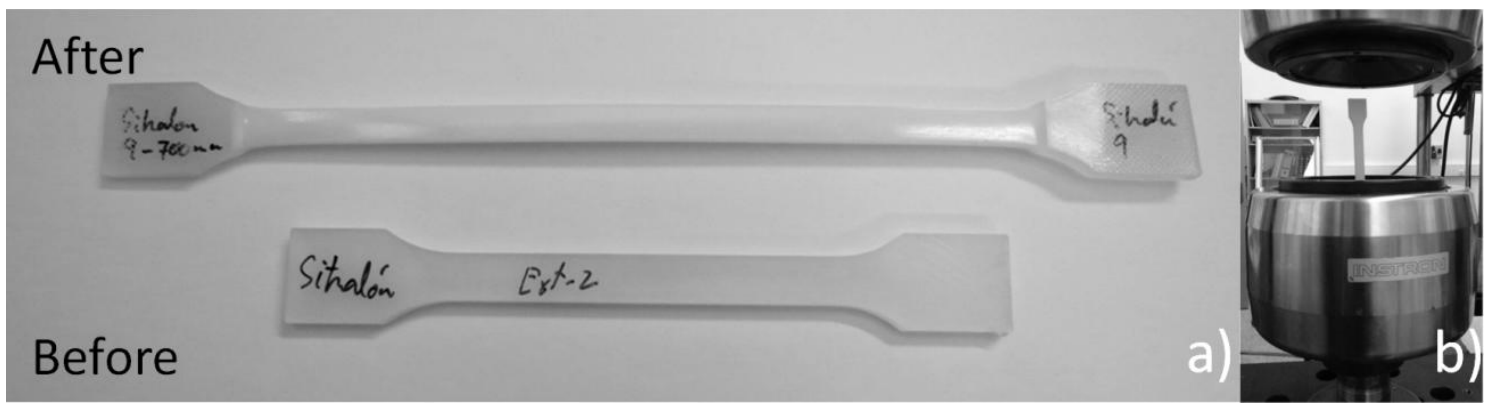

Figure 4. Samples before and after testing.

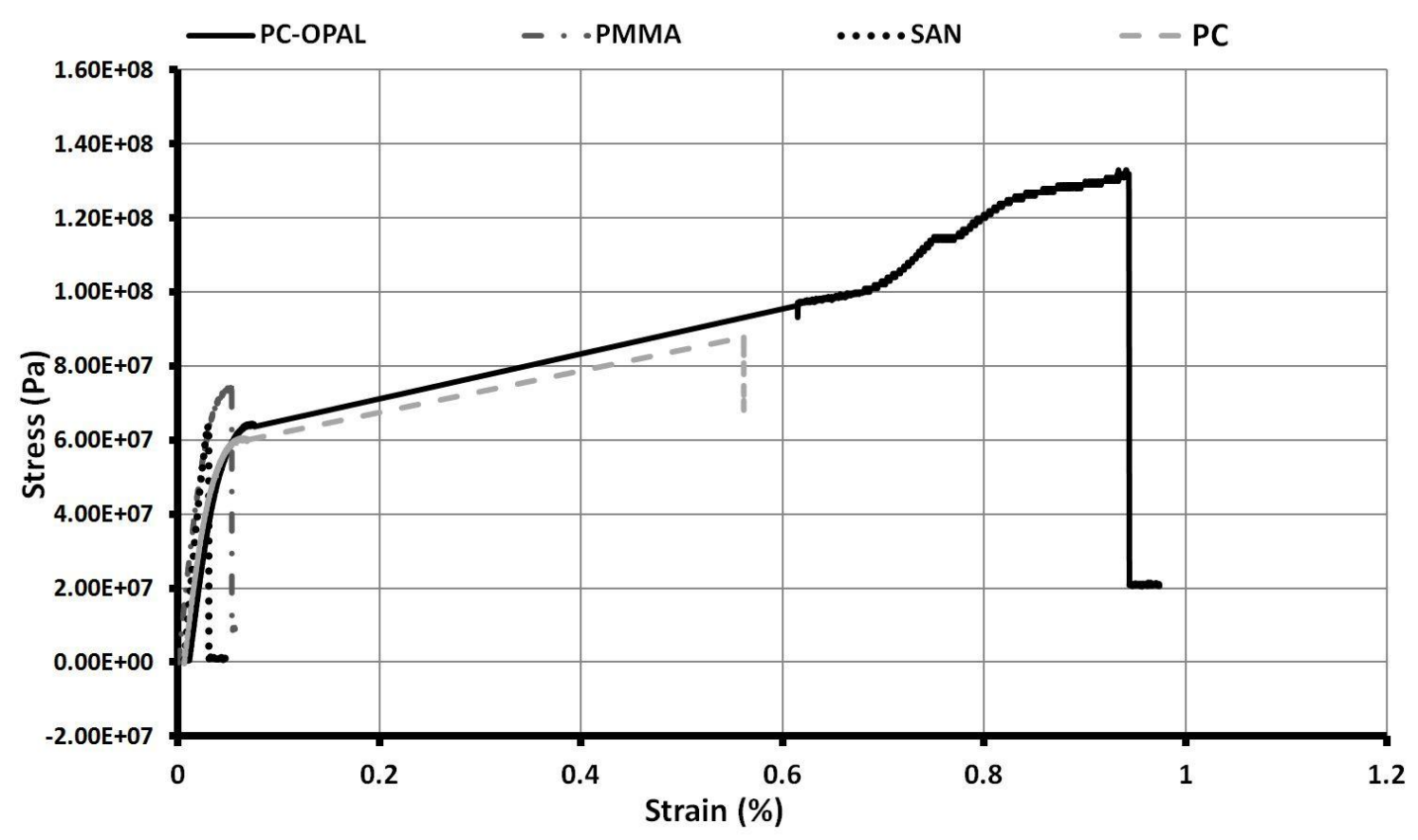

Figure 5. Stress-Strain chart of tested materials 


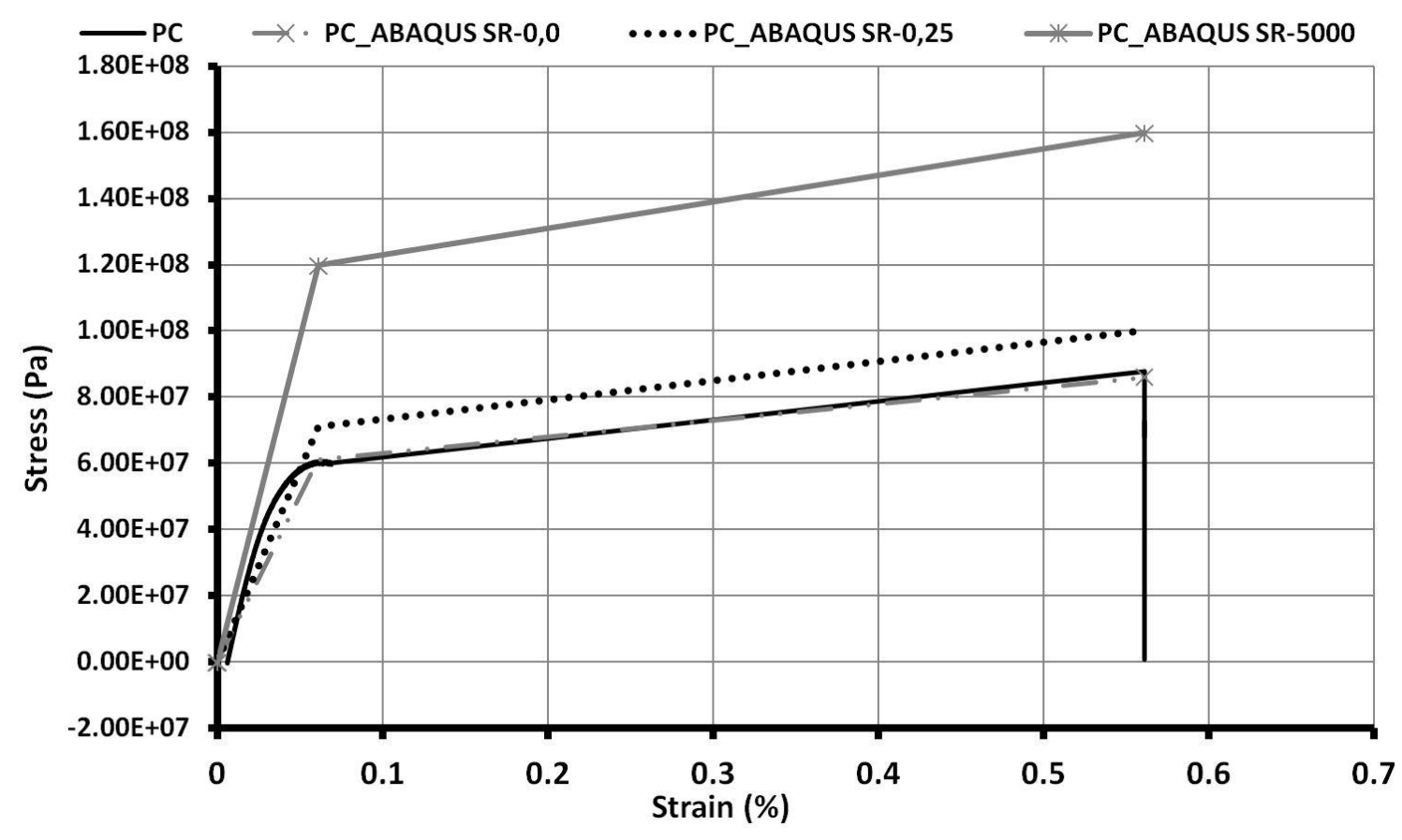

Figure 6. Polycarbonate strain rate material charts for $0,0.25$ and $5000 \mathrm{~s}^{-1}$.

Impact was simulated at both the centre of the specimen and on the end. A complete set of calculations were performed from a minimum thickness of $1 \mathrm{~mm}$ up to the minimum thickness necessary to withstand impact for each material. Those elements in the simulation which cannot withstand the impact are removed, so it can be seen the diffusers crack. Lower thicknesses cause catastrophic failure, with bigger cracks.

Table 2 shows the minimum thickness necessary to withstand impact. Centre refers to impact at the centre of the diffuser, and end refers to the impact on the end. 
The minimum thickness should be the higher of the two load cases. The best material considering these load cases is PC opal. The minimum thicknesses for conventional PC, PMMA and SAN are much greater.

\subsubsection{Thermal simulation}

Thermal behavior is of great importance in sealed luminaires with LED sources, as heat transfer due to convection is lower due to the enclosed housing. A computational fluid dynamics (CFD) model was developed to assess the design, assuring that proper cooling was achieved.

This model was also checked by experimental measurements in steady state conditions, using a thermo-graphic camera and thermocouples for the internal components, such as the electronic control gear or the LEDs. This showed acceptable working temperatures. As the aluminum housing acts as a heatsink, reducing the LED temperatures, and the different materials for the diffuser (PC, SAN, PMMA) have similar thermal properties, the material selection of the diffuser has a minor influence on the thermal behaviour of the luminaire ${ }^{26}$.

\subsubsection{Other simulations}

The ability to manufacture the part has been checked for all the materials with rheological simulations performed with Moldflow. The injection mould has been optimized so as to be able to be injected using PC, PMMA or SAN. The worst case scenario is PC injection as pressures up to $125 \mathrm{MPa}$ are reached. This pressure can be achieved with the injection machines owned by Zalux. Maximum pressure for PMMA is $98 \mathrm{MPa}$, and is even lower, $87 \mathrm{MPa}$, for SAN. Injection simulations were carried out with 4 or 6 hot runners. 
In thermoplastic manufacturing processes, tolerances depend greatly on the type of material used and the overall length of the part. The studied diffuser has a length of $1050 \mathrm{~mm}$, with differences between parts around $1 \mathrm{~mm}$ due to the manufacturing process. This tolerance is taken into account in the design process of the diffuser, housing gasket and closing clips. For smaller dimensions, like the thickness, the tolerances do not have any effect on the functionality of the part, with differences between parts being lower than $0.1 \mathrm{~mm}$. The use of amorphous materials such as PC, SAN and PMMA reduces tolerance problems as the range between minimum and maximum contraction is smaller than in other polymers, such semicrystalline materials.

In order to increase impact resistance, mold injection points are not placed at the edge of the diffuser. Due to molecular orientation and the stress which the polymer can suffer in the injection process, injection points are weaker than the rest of the part. The mold is designed in order to obtain an injection filling process with parameters that create optimal conditions of filling orientation and stress. These injection parameters were also used for the injection of the samples that were tested.

\subsection{Environmental impact assessment}

A simplified life cycle assessment has been performed using SimaPro 7.3.3 software $^{23}$. Most raw materials, production processes, transportation and end-of-life treatments have been selected from the Ecoinvent $\mathrm{v} 2.2^{27}$ and $\mathrm{ELCD}^{28}$ databases of SimaPro. The functional unit has been defined as one diffuser that provides enough impact resistance. Within the limits of the assessment fall raw materials, production processes, transportation and end-of-life. Outside the system is the rest of the 
luminaire, as it is assumed that it will not be affected by the selection of the diffuser material.

The transformation process of "Injection moulding/RER" has been used. Other data have been selected at Spanish (ES) or European (RER) levels ${ }^{29}$.

Transportation by truck from different raw materials has been calculated assuming both the suppliers and the injection factory are located in Alhama de Aragón, Spain (Table 3). Also, the producer-to-consumer transport by truck has been assumed to be $1500 \mathrm{~km}$ for an average European distribution.

Using the Plastics Europe 2012 annual report ${ }^{30}$, an end-of-life scenario of $25.1 \%$ mechanical recycling, 34.1\% energy recovery and $40.8 \%$ land-fill has been assumed. A rough estimation has been used for the recycling process as it is not defined in Ecoinvent v2.2, using a 90\% of avoided production of raw material and an electricity consumption of $0.8 \mathrm{kWh}$ per $\mathrm{kg}$ of recycled waste. Opal PC recycling has also been considered but higher losses (20\%) have been taken into account as the tint used in this polymer can affect its recycling compatibility. ELCD data has been used for energy recovery. Several graphics have been generated to compare the Ecolndicator 99 (Figure 7) and the carbon footprint (Figure 8) results as a function of the diffuser thickness. 


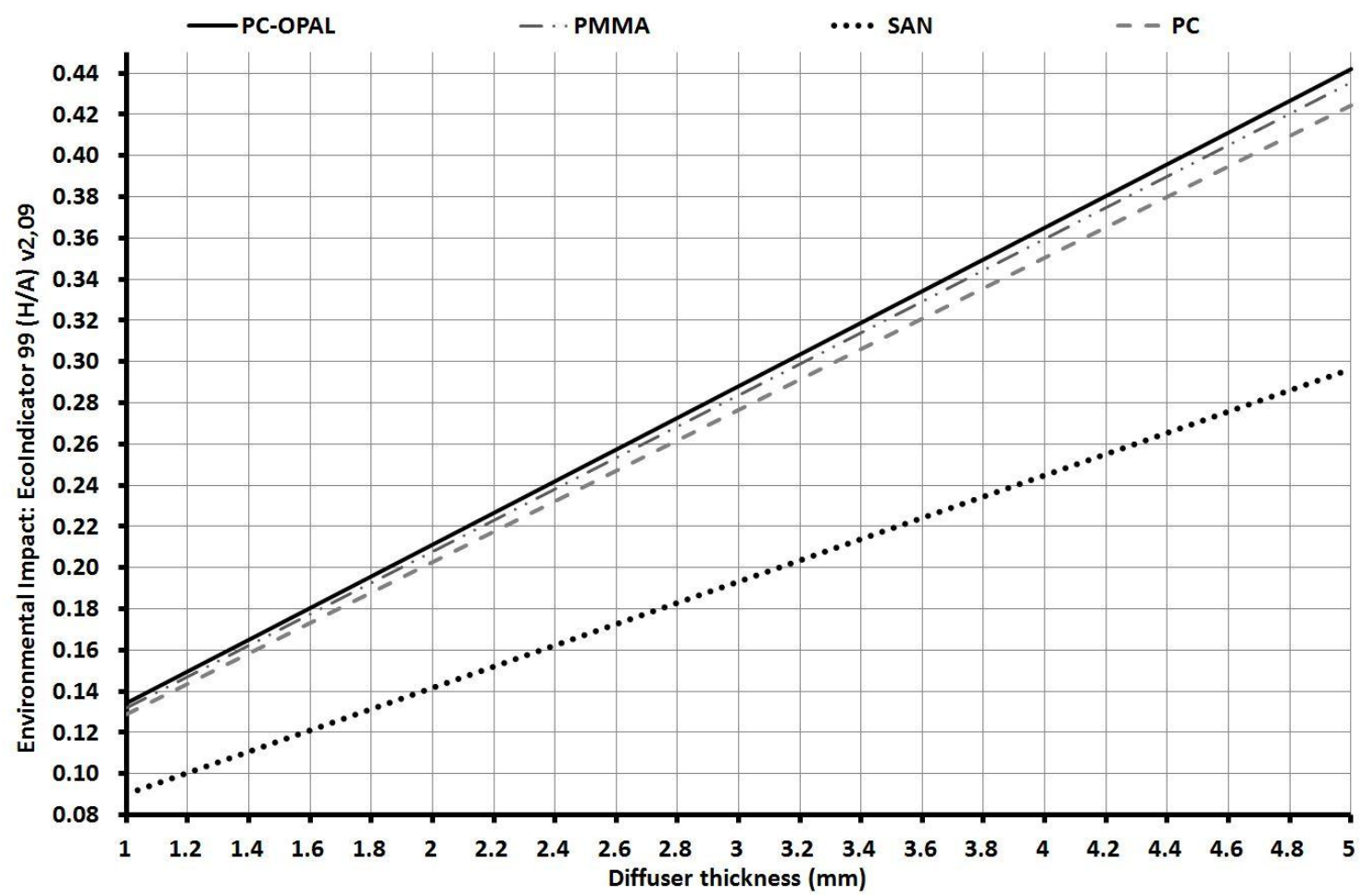

Figure 7. Ecolndicator 99 results for the different materials 


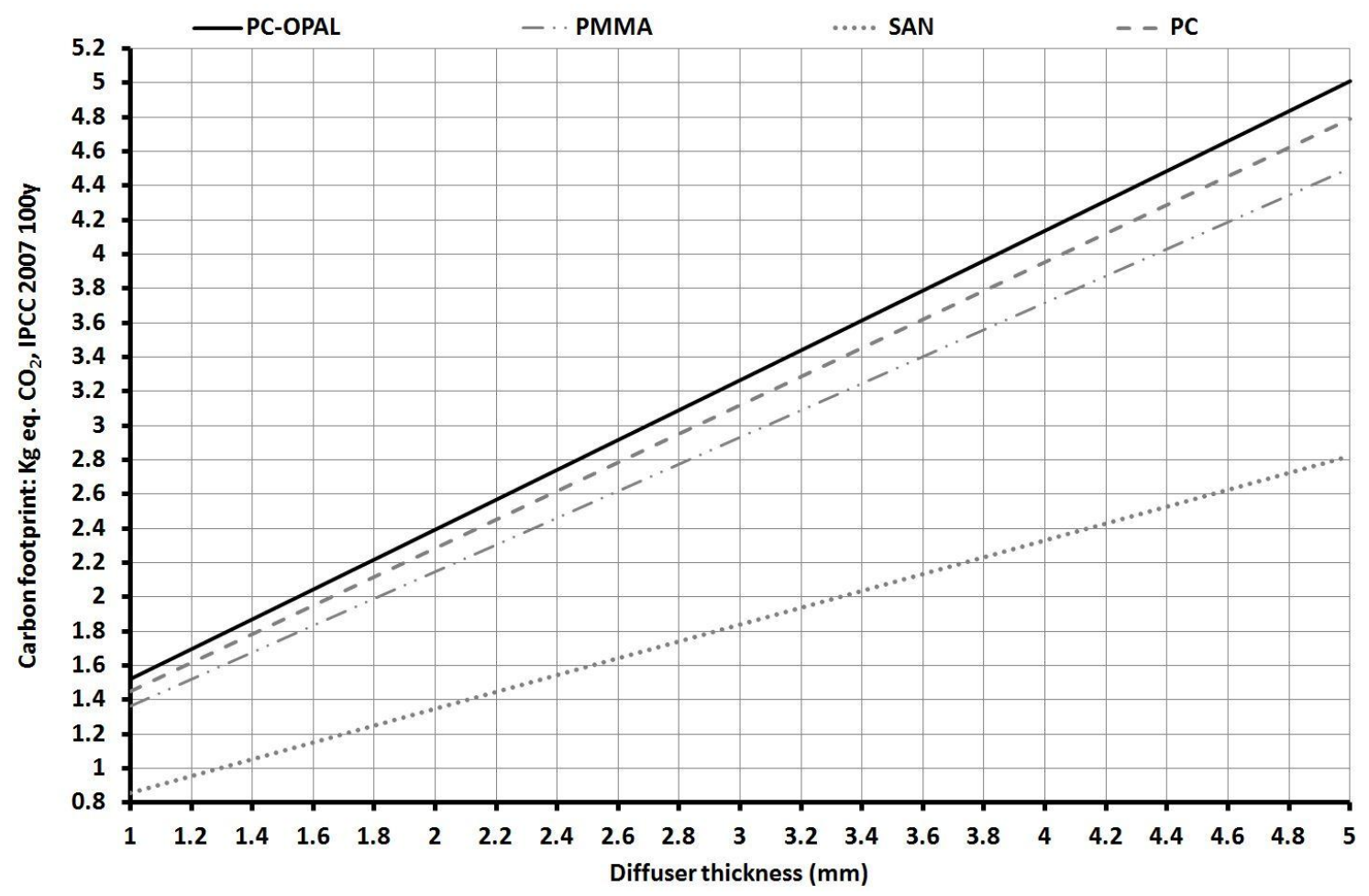

Figure 8. Carbon footprint results for the different materials

\subsection{Economic assessment}

The four proposed materials have been entered into the APPPI software. Each material cost has been calculated using the minimum viable thickness. Thickness and material influences weight and cycle time of the injection process. This software automatically chooses the injection machine and calculates cycle times, taking into account each phase of the injection process. The two most relevant phases are holding and cooling, as these are directly related to the part's thickness. Material also affects cooling times as they are injected at different temperatures. PC is usually injected at higher temperatures, which means longer cooling times ${ }^{31}$. Mould cost has not been 
taken into account as it will not change with the material selection. Figure 9 shows the relationship between the thickness of the diffuser and its total production cost.

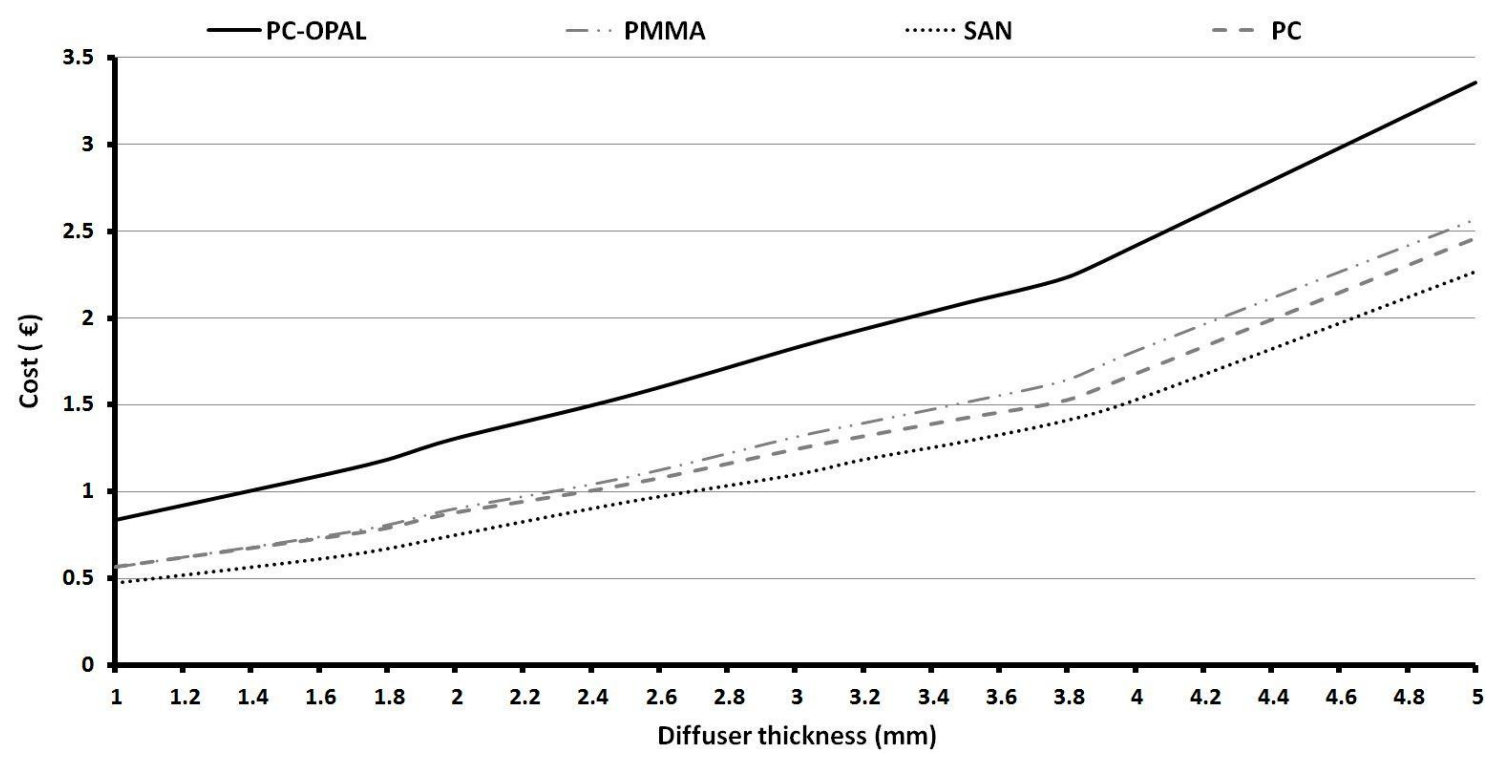

Figure 9. Cost results for the different materials

Table 4 shows for the optimal thickness of each material and all the relevant calculated costs.

\subsection{Comparison and design selection}

Table 5 shows the results for the environmental and economic assessment for the different materials. The lowest environmental impact in this study is produced by the Opal PC as it can be produced with the least thickness. Standard PC also has a very low environmental impact and carbon footprint, whereas PMMA and SAN have higher values and would be discarded, proving that PC is the most environmentally friendly option. 
The environmental impact differences between Opal and Standard PC are small, but there are significant differences in their cost. The evolution of cost is not linear with thickness (Figure 9) as an increase in thickness also increases cycle time, exponentially.

Standard PC has a lower cost and a higher transmission factor and does not need an Opal tint to obtain a proper UGR value. These findings have driven the company to select the standard PC for the diffuser, even though, it does not have the minimum thickness, nor the lowest material cost per $\mathrm{Kg}$ or the minimum processing cost.

\section{Conclusions}

From this work, a methodology has been developed that can be directly used in all lighting systems that have to withstand impacts and adverse weather conditions. With some adaptations, this methodology could also be used to analyze the design of other plastic components. This methodology allows designers to consider technical, economic and environmental factors during the design process, thereby giving a global vision to the design and taking into account the most important factors that affect the performance of the product.

Finite element analysis shows that the critical impact location is the end of the diffuser, due to the low flexibility in this area, which does not allow the diffuser to deform during the impact and thereby absorb the impact energy. The mechanical analysis shows that polycarbonates have an excellent impact behaviour in comparison with acrylic polymers, which allows a reduction in thickness. 
Two different environmental impact methodologies have been used. For this case, both show similar results. Polycarbonate designs have a lower impact than acrylics thanks to their mechanical properties which allow the use of less thickness of material, noticeably reducing the environmental impact.

Economic analysis shows that standard PC is the cheapest option, even though it is not the cheapest material. This is possible thanks to its mechanical properties, which allow less thickness to be used than the acrylic polymers, and this reduces other costs such as processing, with the result that the total cost is the lowest.

After analyzing all the options, the standard PC material has been considered the best selection as it is the cheapest and it has a low environmental impact, a little higher than Opal PC, but clearly lower than acrylics, and it also complies with the mechanical specifications.

\section{Funding}

This research was supported by Zalux S.A.

\section{Acknowledgements}

The authors would like to thank the help provided by the Zalux engineering team. The authors would also like to thank the editor and reviewers for their comments and suggestions.

\section{References}

1. IEC/TC 70. Degrees of protection provided by enclosures for electrical equipment against external mechanical impacts (IK code). ; 2002.

2. Robello DR. Moderately High Refractive Index, Low Optical Dispersion Polymers with 
Pendant Diamondoids. J. Appl. Polym. Sci. 2013; 127(1): p. 96-103.

3. Hamilton DG, Gallucci RR. The Effects of Molecular Weight on Polycarbonate-Polybutylene terephthalate blends. J. Appl. Polym. Sci. 2003; 48(12).

4. Daver F, Demirel B, Sutanto J, Pang CW. An Integrative Simulation Approach to Weight Reduction in Poly(ethylene terephthalate) Bottles. J. Appl. Polym. Sci. 2012; 126: p. E433E439.

5. Pazos M, Baselga J, Bravo J. Limiting thickness estimation in polycarbonate lenses injection using CAE tools. J. Mater. Process. Technol. 2003; 143-144: p. 438-441.

6. ISO. ISO 527-2:2012 Plastics - Determination of tensile properties - Part 2: Test conditions for moulding and extrusion plastics. Geneva:; 2012.

7. Mulliken AD, Boyce MC. Mechanics of the rate-dependent elastic-plastic deformation of glassy polymers from low to high strain rates. Int. J. Solids Struct. 2006; 43: p. 1331-1356.

8. MSC Software Corporation. Patran, Complete FEA Modeling Solution. [Online].; 2014 [cited 2014 Nov 3. Available from: www.mscsoftware.com/product/patran.

9. Dassault Systèmes. Abaqus Unified FEA Complete solutions for realistic simulation. [Online].; 2014 [cited 201411 3. Available from: http://www.3ds.com/productsservices/simulia/products/abaqus/.

10. European Parliament. Directive 2002/95/EC of the European Parliament and of the Council of 27 January 2003 on the restriction of the use of certain hazardous substances in electrical and electronic equipment. ; 2003.

11. European Parliament. Regulation (EC) No 1907/2006 of the European Parliament and of the Council of 18 December 2006 concerning the Registration, Evaluation, Authorisation and Restriction of Chemicals (REACH), establishing a European Chemicals Agency. ; 2006.

12. European Parliament. Directive 2012/19/EU of the European Parliament and of the Council of 4 July 2012 on waste electrical and electronic equipment (WEEE). ; 2012.

13. European Parliament. Directive 2005/32/EC of the European Parliament and of the Council 
of 6 July establishing a framework for the setting of ecodesign requirements for energyusing products. ; 2005.

14. European Parliament. Directive 2009/125/EC of the European Parliament and of the Council of 21 October 2009 establishing a framework for the setting of ecodesign requirements for energy-related products. ; 2009.

15. Martínez E, Jiménez E, Blanco J, Sanz F. LCA sensitivity analysis of a multi-megawatt wind turbine. Appl. Energy. 2010; 87(7): p. 2293-2303.

16. Fernández Á, Javierre C, González J, Elduque D. Development of Thermoplastic Material Food Packaging Considering Technical, Economic and Environmental Criteria. J. Biobased Mater. Bioenergy. 2013; 7(2): p. 176-183.

17. Peças P, Ribeiro I, Folado R, Henriques E. Life Cycle Engineering model for technology selection: a case study on plastic injection moulds for low production volumes. J. Cleaner Prod. 2009; 17(9): p. 846-856.

18. Tähkämo L, Bazzana M, Zissis G, Puolakka M, Halonen L. Life cycle assessment of a fluorescent lamp luminaire used in industry - a case study. Lighting Res. Technol. 2014; 46: p. 453-464.

19. Goedkoop M, Spriensma R. The Eco-indicator 99. A damage oriented method for Life Cycle Impact Assessment. Methodology Report. Amersfoort:; 1999.

20. Solomon, S.; Qin, D.; Manning, M.; Chen, Z.; Marquis, M.; Averyt, K. B.; Tignor, M.and Miller, H.L.. Climate Change 2007 The Physical Science Basis, Contribution of Working Group I to the Fourth Assessment Report of the Intergovernmental Panel on Climate Change Cambridge: Cambridge University Press; 2007.

21. ISO. ISO 14040:2006 Environmental management -- Life cycle assessment -- Principles and framework. Geneva:; 2006.

22. ISO. ISO 14044:2006 Environmental management -- Life cycle assessment -- Requirements and guidelines. Geneva:; 2006. 
23. Goedkoop M, De Schryver A, Oele, Michiel, Durksz S, de Roest D. SimaPro 7. introduction into LCA. Amersfoort, The Netherlands:; 2010.

24. Javierre C, Aísa J, Fernández A, Clavería I. Herramienta CAE para la optimización económica de conjuntos con piezas de plástico inyectadas. Mexico D.F., Mexico: VII, CIDIM'05 Congreso Iberoamericano de Ingeniería Mecánica, Octubre,; 2005.

25. Javierre C. PhD Thesis: Desarrollo de un sistema informático integral que cubre los aspectos técnico-económico en el anteproyecto de una pieza de plástico. , University of Zaragoza; 1999.

26. Javierre $C$, Elduque $D$, Camañes V, Franch D. Simulation and experimental analysis of led weather proof luminaire thermal performance. In 26th European Modeling and Simulation Symposium, EMSS 2014; 10-12 September, 2014; Bordeaux; France. p. 517-522.

27. Weidema B, Hischier R. ecoinvent data v2.2. St. Gallen: Swiss Centre for Life Cycle Inventories; 2010.

28. EU/JRC/IES/EPLCA. European reference Life Cycle Database. [Online].; 2014 [cited 201410 29. Available from: http://lca.jrc.ec.europa.eu/.

29. Frischknecht, Rolf; Jungbluth, Niels; Althaus, Hans-Jörg; Doka, Gabor; Dones, Roberto; Heck, Thomas; Hellweg, Stefanie; Hischier, Roland; Nemecek, Thomas; Rebitzer, Gerald and Spielmann, Michael. The ecoinvent Database: Overview and Methodological Framework. Int. J. Life Cycle Assess. 2005; 10(1): p. 3-9.

30. Plastics Europe. Plastics - the Facts 2012. An analysis of European plastics production, demand and waste data for 2011. ; 2012.

31. Abdallah W, Yilmazer U. Polyamide 66 Nanocomposites Based on Organoclays Treated with Thermally Stable Phosphonium Salts. J. Appl. Polym. Sci. 2013; 127(1): p. 772-783. 


\section{Figure captions}

Figure 1. The Nextrema weatherproof luminaire

Figure 2. Working methodology diagram

Figure 3. Simulation model and impact test

Figure 4. Samples before and after testing.

Figure 5. Stress-Strain chart of tested materials

Figure 6. Polycarbonate strain rate material charts for $0,0.25$ and $5000 \mathrm{~s}^{-1}$.

Figure 7. Ecolndicator 99 results for the different materials

Figure 8. Carbon footprint results for the different materials

Figure 9. Cost results for the different materials 
Table 1. Relation between IK number and impact energy

\begin{tabular}{ll}
\hline IK & Impact energy $(\mathrm{J})$ \\
\hline 00 & 0 (without protection) \\
01 & 0.15 \\
02 & 0.20 \\
03 & 0.35 \\
04 & 0.5 \\
05 & 0.7 \\
06 & 1 \\
07 & 2 \\
08 & 5 \\
09 & 10 \\
10 & 20 \\
\hline
\end{tabular}


Table 2. Minimum thickness for the different materials

\begin{tabular}{lcccc}
\hline & PC Opal & PC & PMMA- & SAN \\
\hline Centre $(\mathrm{mm})$ & 1.5 & 1.7 & 3 & 3.5 \\
End $(\mathrm{mm})$ & 1.6 & 1.8 & 3.2 & 3.8 \\
\hline
\end{tabular}


Table 3. Distances of the material producers

\begin{tabular}{lll}
\hline Material & Distance to supplier $(\mathrm{km})$ & Transport Mode \\
\hline PC OPAL & 1624 & Truck \\
PC & 1624 & Truck \\
PMMA & 1671 & Truck \\
SAN & 1651 & Truck \\
\hline
\end{tabular}


Table 4. Economic factors of each material for their optimal thickness.

\begin{tabular}{lllll}
\hline & PC Opal & PC & PMMA & SAN \\
\hline Minimum thickness $(\mathrm{mm})$ & 1.6 & 1.8 & 3.2 & 3 \\
Volume $(\mathrm{cm} 3)$ & 230.76 & 251.55 & 392.01 & 407.96 \\
Density $(\mathrm{g} / \mathrm{cm} 3)$ & 1.19 & 1.19 & 1.19 & 1.08 \\
Material cost $(€ / \mathrm{Kg})$ & 3.885 & 2.31 & 2.26 & 2.07 \\
Cycle time $(\mathrm{s})$ & 21.0 & 22.5 & 55.9 & 62.6 \\
Processing cost $(€)$ & 0.188 & 0.201 & 0.499 & 0.46 \\
Material cost $(€)$ & 1.077 & 0.696 & 1.045 & 0.95 \\
Total cost $(€)$ & 1.345 & 0.977 & 1.62 & 1.55 \\
\hline
\end{tabular}


Table 5. Environmental impact and cost results for the different materials at the minimum functional thicknesses.

\begin{tabular}{ccccccc}
\hline Material & $\begin{array}{c}\text { Minimum } \\
\text { functional } \\
\text { thickness } \\
(\mathrm{mm})\end{array}$ & $\begin{array}{c}\text { Weight } \\
\text { (grams) }\end{array}$ & $\begin{array}{c}\text { Environmental } \\
\text { Impact (Pt } \\
\text { Ecol99 H/A) }\end{array}$ & $\begin{array}{c}\text { Carbon } \\
\text { footprint } \\
\text { (Kg CO2 } \\
\text { eq.) }\end{array}$ & $\begin{array}{c}\text { Material } \\
\text { Cost }(€)\end{array}$ & $\begin{array}{c}\text { Total } \\
\text { Cost } \\
(€)\end{array}$ \\
\hline PC Opal & 1.6 & 231 & 0.18027 & 2.04280 & 0.897 & 1.094 \\
PC & 1.8 & 252 & 0.18780 & 2.11866 & 0.582 & 0.731 \\
PMMA & 3.2 & 385 & 0.29875 & 3.09047 & 0.870 & 1.395 \\
SAN & 3.8 & 412 & 0.23445 & 2.23341 & 0.853 & 1.413 \\
\hline
\end{tabular}

